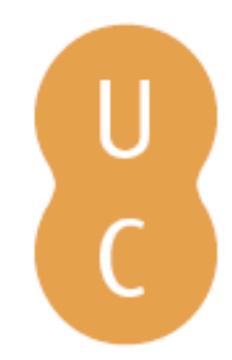

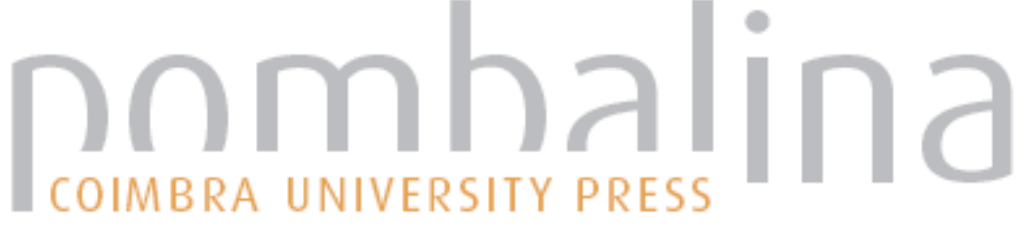

Crise, corrupção política e media

Autor(es): $\quad$ Cunha, Isabel Ferin

Publicado por: Imprensa da Universidade de Coimbra

URL

persistente: $\quad$ URI:http://hdl.handle.net/10316.2/30729

DOI: $\quad$ DOI:http://dx.doi.org/10.14195/978-989-26-0574-6_7

Accessed : $\quad$ 26-Apr-2023 15:44:22

A navegação consulta e descarregamento dos títulos inseridos nas Bibliotecas Digitais UC Digitalis, UC Pombalina e UC Impactum, pressupõem a aceitação plena e sem reservas dos Termos e Condições de Uso destas Bibliotecas Digitais, disponíveis em https://digitalis.uc.pt/pt-pt/termos.

Conforme exposto nos referidos Termos e Condições de Uso, o descarregamento de títulos de acesso restrito requer uma licença válida de autorização devendo o utilizador aceder ao(s) documento(s) a partir de um endereço de IP da instituição detentora da supramencionada licença.

Ao utilizador é apenas permitido o descarregamento para uso pessoal, pelo que o emprego do(s) título(s) descarregado(s) para outro fim, designadamente comercial, carece de autorização do respetivo autor ou editor da obra.

Na medida em que todas as obras da UC Digitalis se encontram protegidas pelo Código do Direito de Autor e Direitos Conexos e demais legislação aplicável, toda a cópia, parcial ou total, deste documento, nos casos em que é legalmente admitida, deverá conter ou fazer-se acompanhar por este aviso.

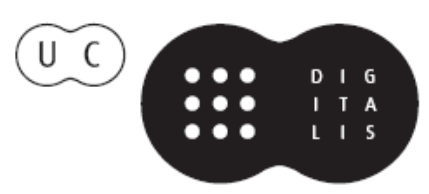




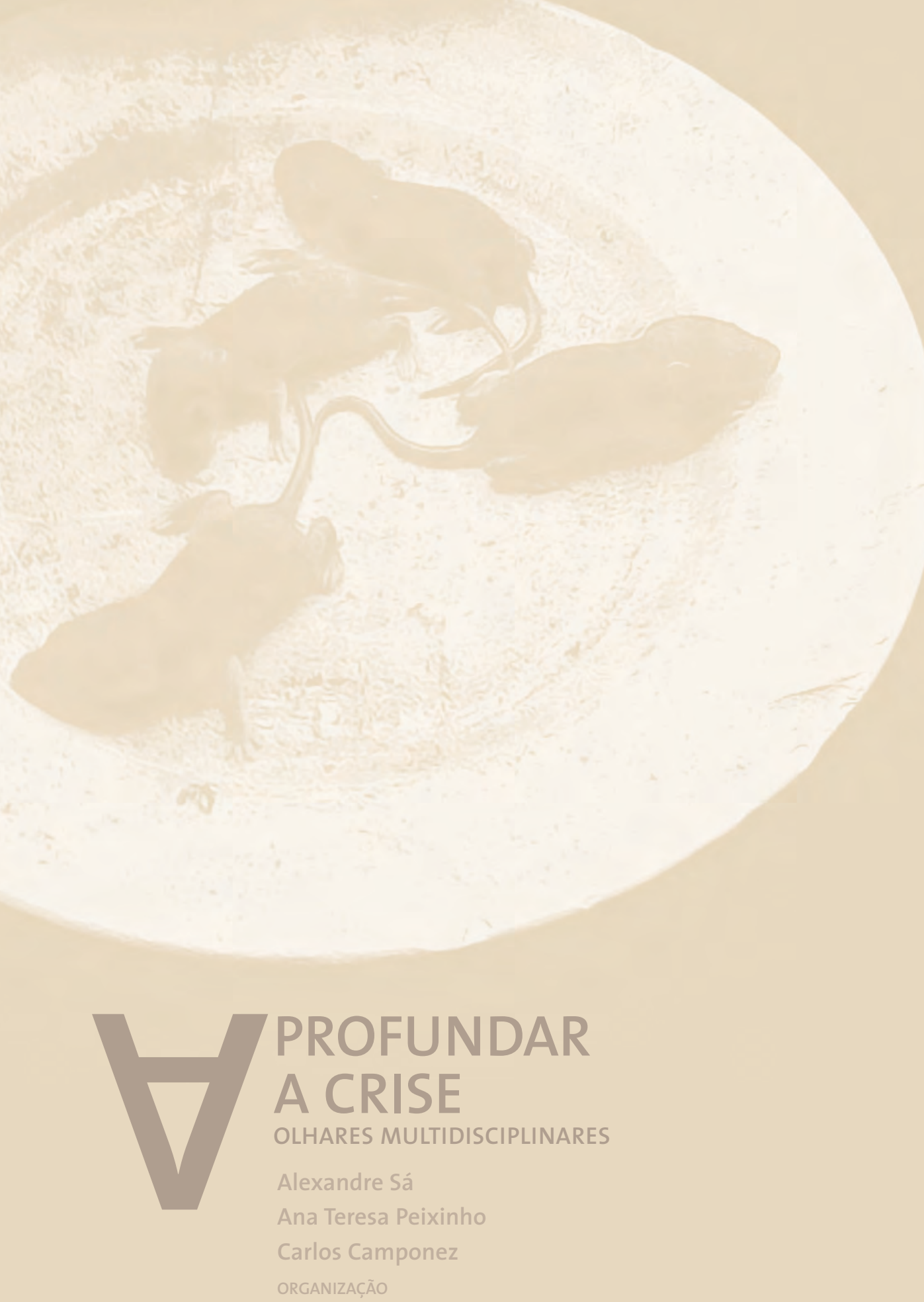


Isabel Ferin Cunha

FLUC

\section{Crise, Corrupção Política e Media}

\section{Introdução}

Este artigo tem como objetivo discutir as relações entre crise, corrupção política e os media. Inicia-se a exposição apresentando diversas aceções dos conceitos anteriormente referidos, tendo em conta a sua etimologia, as definições de dicionários gerais e das áreas disciplinares, bem como os conceitos apresentados nos estudos sobre os media e à ciência política. Disserta-se sobre os conceitos de crise e corrupção política tendo como exemplos o contexto europeu e português Em seguida, recorrendo-se a uma revisão da literatura, estabelece-se as relações entre crise e corrupção política destacando-se os fatores singulares que estão na génese da atual crise internacional e portuguesa. Estas reflexões serão posteriormente conectadas aos fenómenos de corrupção e às suas representações nos media bem como ao papel que estes exercem na denúncia e prevenção. Apoiam-se estas afirmações nos estudos realizados pela organização não-governamental Transparência Internacional e nos índices que divulga, assim como nos estudos sobre as perceções sociais da corrupção em Portugal. Salienta-se, ainda, as questões relativas à transparência da informação e dos processos de comunicação sobre a governação presentes nos media.

Ao longo do artigo toma-se como exemplo alguns estudos empíricos sobre a cobertura de atos de democracia na imprensa e na televisão e apresentam-se algumas imagens a título ilustrativo. Esta estratégia tem como objetivo cotejar definições concetuais e a revisão de literatura com as representações da crise e da corrupção política nos meios de comunicação. 
Etimologicamente a palavra crise tem a sua origem no grego krisis, que significa separação, disputa, decisão, sentença ou juízo definitivo. No latim crisis designa alteração, desequilíbrio repentino; estado de dúvida e incerteza; tensão, conflito (Cunha, 1982: 228). A origem etimológica de crise e os seus sentidos, assim como as definições encontradas nos dicionários gerais, apontam para variados campos disciplinares, como a medicina - alteração para melhor ou para pior no curso de uma doença - a economia - momento decisivo de um negócio - e a política, quando um governo, partido ou político, se encontra em dificuldades ou quando há um hiato de poder. A palavra crise pode também estar associada à moral e resultar de um conflito de sentimentos ou valores.

Norberto Bobbio no seu Dicionário de Política (2004: 303-306) define crise como um momento de rutura no funcionamento de um sistema e considera que as crises podem ser caraterizadas através de três elementos: imprevisibilidade, duração limitada e incidência no funcionamento do sistema. Para compreender uma crise é necessário ter em conta os contextos internos e externos que a antecedem e as mudanças no sistema que a originaram. Na fase da crise, propriamente dita, deve-se dar especial relevância para as questões de tempo e espaço que uma crise envolve e para os atores e protagonistas que se encontram em jogo. Bobbio considera que as crises políticas e as crises económicas estão intrinsecamente ligadas, tanto a nível nacional como internacional, como demonstra a crise económica internacional de 1929 a 1932 que teve severas repercussões sobre os sistemas políticos nacionais. Assim, as crises podem ter uma origem interna ou externa ao sistema e evoluírem em função de picos, o que quer dizer que ao longo da duração de uma crise podem sobrepor-se outras crises, provocando sobrecargas nos sistemas políticos, económicos, jurídicos e sociais.

O mesmo autor distingue ainda as crises do sistema, as governamentais e as internacionais. A crise do sistema está associada a alterações do regime político, bem como a mudanças nos mecanismo e dispositivos jurídicos e constitucionais, como por exemplo, o fim de um regime monárquico e a implantação de uma república, ou o fim de um regime ditatorial e o início de uma democracia. Ainda dentro da crise do sistema, inscrevem-se as transformações das relações 
socioeconómicas que incluem as relações de produção, a distribuição de propriedade e de rendimentos e a conceção de família (Bobbio, 2004: 304). Convém notar que os dois aspetos focados estão profundamente interligados, o que faz com que não haja mudanças de regime sem alterações nas relações socioeconómicas, nem alterações socioeconómicas sem substanciais mudanças na conceção e desenho de um regime.

As crises governamentais estão relacionadas ao funcionamento do subsistema Governo e podem ter origem em fatores internos, inerentes ao contexto e estrutura governamental, ou externos, referentes às relações com a sociedade ou com aspetos derivados de conjunturas internacionais desfavoráveis. O autor assinala que um dos elementos determinantes da crise de governo advém das relações entre classe política e sociedade e pode depender da falta de representatividade da classe política no poder sendo que a institucionalização dos procedimentos com vista a solucionar as crises governamentais têm como objetivo controlar os danos que possam afetar o regime (Bobbio, 2004: 3005).

Crise internacional é um conceito que teve a sua origem nas relações diplomáticas e políticas entre países. Historicamente o conceito esteve sempre associado a conflitos, a guerras e às ambições hegemónicas de determinados países. Na modernidade este conceito aplica-se às relações económicas e às disputas entre países, encabeçadas por partidos e grupos de interesses instalados nos governos, empreendidas com vista a obter vantagens económicas, financeiras e tecnológicas relativamente a acordos. Segundo Bobbio (2004: 305) há uma enorme vantagem em analisar as crises internacionais do ponto de vista da informação disponível, da qualidade e número dos atores envolvidos, bem como dos processos de decisão e resultados alcançados.

A recente crise internacional eclodiu nos mercados em setembro de 2008 despoletada pela falência do banco Lehman Brothers mas, em Portugal, vinha-se arrastando desde o início do milénio, com crescente endividamento interno e externo, baixas taxas de crescimento do PIB, aumento do desemprego e dificuldades em enfrentar a abertura aos mercados emergentes. Apesar do governo socialista, que tomou posse em fevereiro de 2005, ter nos primeiros anos de legislatura reequilibrado o défice e ter dado algum folgo à economia, a crise internacional acabou por vir anular estes esforços. A crise internacional atinge sobretudo o Ocidente, Europa e Estados Unidos, com grandes défices públicos 
e privados e crónica dependência de financiamento externo. Países emergentes, como o Brasil, a China, a Índia e a Rússia, não têm sido afetados da mesma maneira estimando-se crescimentos económicos entre os quatro e os oito por cento.

\section{Crise e corrupção}

No grego, a palavra phthora, corrupção, é o contrário do termo geração sendo que ambos os conceitos apontam para a mudança substancial de caraterísticas que estão associadas à natureza das coisas que podem "chegar a ser" (geração) e "deixar de ser" (corrupção). Assim, para Aristóteles (2005), a corrupção é um movimento de mudança das coisas da natureza, que vai do algo ao não ser desse algo. Nesta aceção, a degeneração, putrefação ou destruição é um processo profundo da transformação dos seres, não necessariamente negativo, que tem em vista a mudança de sua matéria. O conceito de corrupção, do latim corruptione, surge no Dicionário etimológico da língua portuguesa (Cunha, 1982: 203) com dois campos semânticos paralelos. O primeiro aponta para a ideia de estragar e decompor; o segundo envolve um sentido moral mais evidente como perverter e depravar. Estes campos semânticos acentuam a visão "negativa" da conceção de corrupção enunciada pela definição grega e por Aristóteles, ao mesmo tempo que alastram aos sentidos que envolvem a utilização da palavra crise na atualidade.

Rose-Ackerman (1999) na discussão que empreende sobre crise e corrupção, reflete que a crise gera mudanças políticas, económicas, sociais e morais. Ao mesmo tempo, ela é um fenómeno que provoca o afastamento dos cidadãos dos seus governantes e tende a provocar uma despolitização do espaço público, abrindo campo a uma deslegitimação do sistema político e das instituições públicas. A economia é o vetor preponderante das crises na história contemporânea, ten-

dendo a defraudar as expectativas dos cidadãos e das sociedades e contribuindo, de forma inequívoca, para o aumento de fenómenos de corrupção, nas suas múltiplas variantes. Acresce que as crises provocam, também, uma escalada de reivindicações sociais que, por sua vez, levam os atores e agentes políticos e económicos a limitar direitos políticos e sociais, nomeadamente através do controle da informação. As crises promovem ainda o escamoteamento de aspetos 
micro e macropolíticos e processos de colonização económica dos discursos no espaço público, desenrolando-se, em simultâneo, estratégias de ocultação e manipulação da informação disponível.

Gambetta (2002) defende que, na linguagem comum, corrupção carrega diversos sentidos, sendo que três parecem ser os mais importantes. Numa primeira aceção, corrupção refere-se à degradação do sentido ético de agentes (públicos ou privados) implicando uma falta de integridade moral e a sua consequente depravação. Numa segunda perspetiva, corrupção surge associada a um conjunto de práticas sociais resultantes da degradação de algumas instituições (públicas e privadas), estando por isso o foco da corrupção nas relações institucionais e na organização da sociedade. Um terceiro sentido de corrupção acentua determinadas práticas sociais, com forte componente cultural, como por exemplo presentes, etc., com vista a favorecer ou premiar decisões de agentes públicos ou privados.

A literatura especializada e os media classificam corrupção como um conjunto de ilícitos, de grau e natureza diversos que vão dos "agrados" ao compadrio, à cleptocracia, aos crimes de colarinho-branco e à criminalidade organizada. No entanto, a definição de corrupção, entendida como uma prática, é um fenómeno sui generis com propriedades específicas, que se distingue de outros fenómenos de apropriação indevida, encontrando-se hoje relativamente estabilizada. A perceção social de corrupção envolve elementos de cultura local e nacional, variando, em função dos períodos e dos países, a noção do que é legítimo e legal. Em alguns países, os donativos aos partidos são contra a lei, mas noutros não e em certas circunstâncias são aceitáveis: In Italy the socialist argued that the bribes they took were for their party rather than for personal gain, and that, since there is no other way for them to finance their electoral campaigns, donations should be legalized (Gambetta, 2002: 34)

Assume-se assim que a perceção social da corrupção está inserida na cultura local e nacional e tem que ser enquadrada numa perspetiva diacrónica e sincrónica. Como exemplo, pode-se citar determinadas formas de clientelismo em países do Leste da Europa que sempre estiveram na base da organização social e que no pós-comunisno se fundiram com a corrupção. Para Sajó (2002: 1-21) deve-se fazer uma distinção entre atos individuais de corrupção e as estruturas sociais 
clientelistas, independentemente destas abrigarem, frequentemente, práticas corruptas. Segundo ainda este autor, estes fenómenos acabaram misturando-se no que chama clientelistic corruption tornando-se uma forma estável de organização social que permeia todas as áreas da vida pública. O fim do estado comunista e a consequente fragilidade da economia e das instituições fez com que as populações não tivessem uma perceção clara sobre os efeitos da corrupção quer sobre os procedimentos clientelísticos tradicionais, quer sobre a emergência de novas práticas de corrupção.

A definição mais abrangente de corrupção diz respeito à apropriação indevida de bens ou ganhos, enquanto o esmiuçar do conceito aponta para três grandes cenários: um primeiro em que ocorre uma degradação do sentido ético dos agentes envolvidos; um segundo em que se observa um conjunto de práticas sociais predatórias no interior de determinadas instituições e um terceiro cenário onde instituições e agentes acordam na apropriação indevida de benefícios (Heidenheimer e Johnston, 2002: 3-73).

Segundo Dobel (1978) a corrupção deriva, em grande parte, da escassez de bens disponíveis num determinado momento numa dada sociedade o que tende a promover uma "luta pela sobrevivência" aliada a uma diminuição dos padrões éticos e cívicos. Dobel considera que, neste contexto, os ilícitos surgem sobre a forma de corrupção política, económica e judiciária mas é na política que esta se torna mais evidente em cenários de crise económica. Salienta ainda que a corrupção política é um fenómeno historicamente inerente aos contextos de crise e aos fins de regime que esteve sempre no Ocidente associada às crises de legitimação, em que os atores (cidadãos e políticos) qualificam a ordem política como corrupta e empreendem ações com vista à sua alteração.

Na comunicação social portuguesa, as referências à crise são frequentes desde o início do milénio. Estudos empíricos sobre as coberturas dos finais de mandato de primeiros-ministros (Cavaco Silva, 1994-1995; António Guterres, 2001-2002; Santana-Lopes, 2004-2005) na imprensa de referência registam como tema recorrente as questões sobre o défice e a economia (Ferin, 2006: 30-38), bem como sobre a"crise", como se pode ver com duas capas de jornais periódicos publicadas no final de mandato do primeiro-ministro Cavaco Silva (1995). 

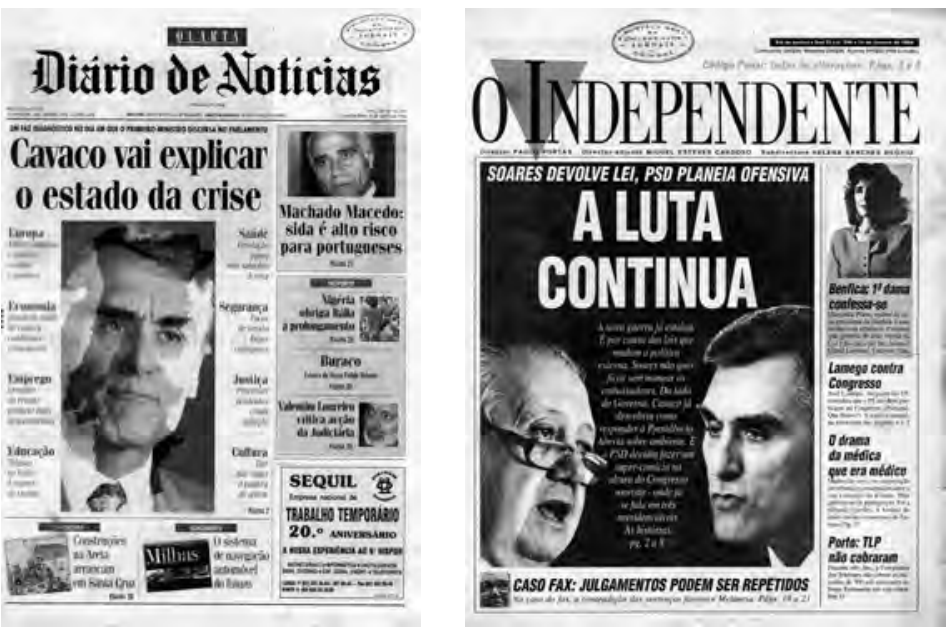

Fonte: Ferin, I. (coord.) (2007)

Na cobertura das eleições legislativas de 2005 (Memorandum, 2005) entre os temas dominantes das candidaturas, embora ainda apresentados sobre diversas perspetivas, estão já assinalados a situação das finanças e a alusão a ilícitos na governação.

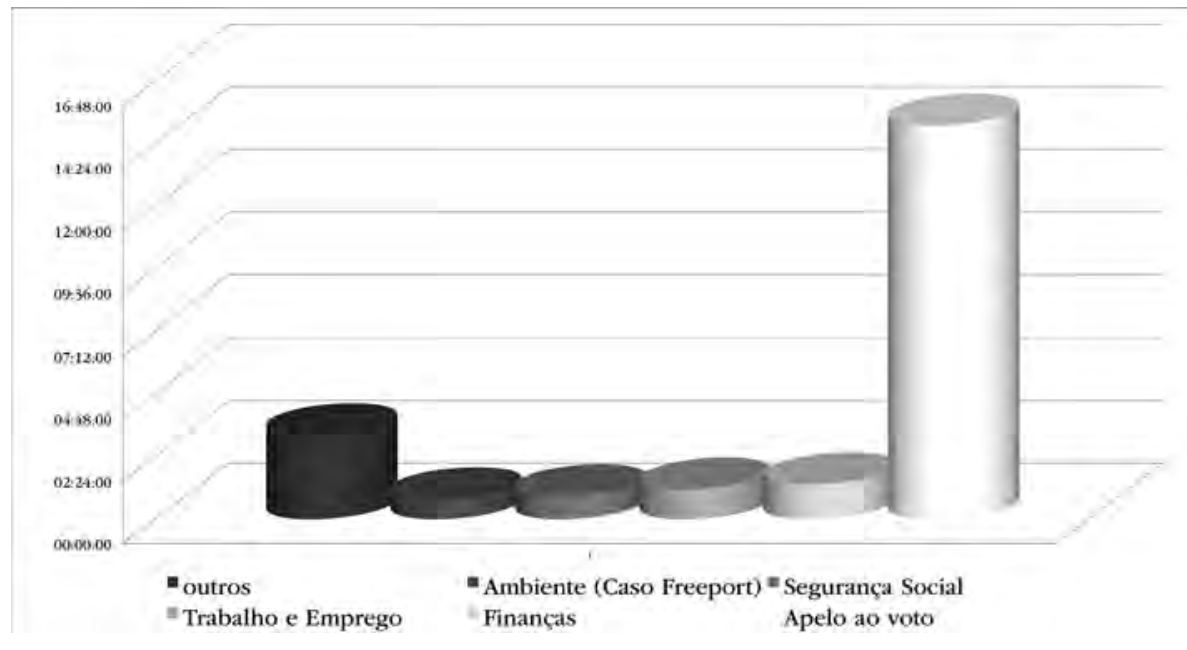

Fonte: Memorando, Legislativas 2005 
Num estudo empírico realizado pelo CIMJ (Centro de Investigação Media e Jornalismo), solicitado pela Entidade Reguladora da Comunicação, sobre as Legislativas de 2009, os temas mais focados nos canais generalistas pelos partidos, num total de 1043 registos, foram, "Ações de Campanha" (42, 3\%, 441 registos), "Economia, Finanças e Crise" (19, 9\%, 208 registos), "Ambiente" (6, 0\%, 63 registos) e "Escândalos e Processos judiciais" (5, 4\%, 56 registos). Nos canais de acesso condicionado, num total de 630 registos, os temas "Escândalos e Processos Judiciais" (9, 7\%, 61 registos) e "Economia, Finanças e Crise" (4, 9\%, 31 registos) ocupam, respetivamente, o terceiro e quarto lugar na cobertura das eleições.

Estes exemplos retirados de estudos empíricos sobre atos de democracia ilustram que a associação entre crise e corrupção tem estado permanentemente nos meios de comunicação e apresentam grande visibilidade no espaço público mediático português. Esta visibilidade justifica que, nos últimos cinco anos (2005-2010), a perceção pública sobre o aumento da corrupção em Portugal tenha vindo a refletir-se nas alterações de posição do país na listagem divulgada anualmente pela Transparency International no Global Report. Em 2006,

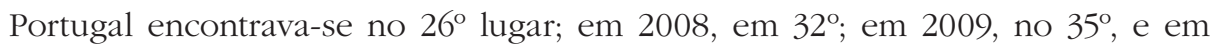
2010 voltou à $32^{\mathrm{a}}$ posição.

\section{Corrupção política}

A corrupção política é entendida como o abuso de poder em benefício próprio de agentes políticos democraticamente eleitos. Esta situação pode ocorrer durante o exercício de funções públicas, ou após, quando os agentes políticos utilizam o capital relacional adquirido durante o exercício de funções para a obtenção de ganhos indevidos. Este processo envolve um leque diversificado de crimes cometidos por agentes políticos ou ex-agentes políticos. Os ilícitos ocorrem fundamentalmente em quatro situações-tipo: na competição por cargos políticos, no exercício de cargos públicos, na ação de legislar e governar, bem como após o abandono de cargos de governação, mantendo-se, contudo, determinadas funções político-partidárias (Heidenheimer e Johnston, 2002).

A corrupção política articula as áreas da Política (poder), da Economia (empresas e negócios), da Justiça (quadro legal) e dos Media (publicitação da 
informação) (Blankenburg, 2002). Simultaneamente, os tipos mais frequentes de corrupção política surgem sob a forma de fraude, suborno, clientelismo, apropriação indevida de bens, tráfico de influências, favorecimento seletivo e financiamento ilegal de partidos.

Bobbio (2004: 291-292) distingue três tipos de corrupção: a recompensa ou compra de um funcionário público no sentido de influenciar a sua decisão; o nepotismo ou contratação de funcionários baseada em relações de parentesco e não no mérito; o peculato por desvio ou apropriação de fundos públicos para fins privados. O autor considera ainda que a corrupção é uma forma particular de exercer influência que tende a moldar-se ao sistema em que se insere, nomeadamente no que toca à tomada de decisões. Neste sentido, a institucionalização de certas práticas torna previsível o aumento de corrupção, sendo que quanto maior for o âmbito da institucionalização maior será a probabilidade do sistema se corromper.

Bobbio (2004), Blankenburg (2002) e Philp (2002) consideram que as privatizações realizadas no espaço europeu alargado nas décadas de oitenta e noventa contribuíram para o aumento da corrupção em diversos níveis. Salientam, primeiramente, que a mudança de paradigma económico e financeiro veio favorecer determinados grupos de interesses já instalados, que viram aumentados os seus privilégios, assumindo estratégias - tais como a alternância de gestores entre cargos públicos e privados - com vista a influenciar decisões governamentais. A expansão económica e financeira, e o crescimento da sociedade de consumo, nas décadas de oitenta e noventa na Europa, fizeram igualmente emergir uma nova elite dirigente, cujos valores conjugaram práticas políticas tradicionaiscomo clientelismo, nepotismo e familiarismo- com estratégias de sucesso e enriquecimento rápido.

Um dos exemplos deste conjunto de práticas está elencado na cronologia do "Caso Freeport" publicada no Diário de Notícias de 27 de Julho de 2010, que se transcreve em seguida:

MP ENCERROU INVESTIGAÇÃO

Freeport: Cronologia dos principais acontecimentos

27 Julho 2010

Cronologia dos principais acontecimentos relacionados com o processo Freeport, que teve na sua origem suspeitas de corrupção e tráfico de 
influências na alteração à Zona de Protecção Especial do Estuário do Tejo e licenciamento do espaço comercial em Alcochete quando era ministro do Ambiente José Sócrates, actual primeiro-ministro.

Entre os arguidos estão os empresários Charles Smith e Manuel Pedro, João Cabral, funcionário da empresa Smith\&amd Pedro, o arquiteto Capinha Lopes, o antigo presidente do Instituto de Conservação da Natureza Carlos Guerra e o então vice-presidente deste organismo José Manuel Marques e o ex-autarca de Alcochete José Dias Inocêncio.

2002

- Em Março é aprovado o Estudo de Impacte Ambiental do projecto para o 'outlet' Freeport em Alcochete. O projecto já tinha sido chumbado duas vezes. No mesmo dia é decretada no último Conselho de Ministros uma alteração da Zona de Protecção Especial (ZPE) do Tejo que exclui o terreno do 'outlet'.

- Em Junho a Quercus apresenta duas queixas na União Europeia: uma contra o licenciamento e outra contra a alteração da ZPE.

2004

- Em Setembro é inaugurado o espaço comercial Freeport. Com uma área global equivalente a 55 estádios de futebol, o complexo de Alcochete custou cerca de 250 milhões de euros. É o maior outlet da Europa.

- Em Outubro chega à PJ de Setúbal uma carta anónima, que se soube mais tarde ser de Zeferino Boal, então deputado municipal do CDS/PP em Alcochete, que denunciava o alegado financiamento do PS a troco da aprovação do Freeport numa altura em que José Sócrates era ministro do Ambiente e na altura candidato a primeiro-ministro. A Polícia Judiciária (PJ) começa a investigar.

2005

- O semanário 'O Independente' divulgou que José Sócrates foi dado como sendo suspeito de alterar a Zona de Proteção Especial (ZPE) do Estuário do Tejo enquanto ministro do Ambiente.

- Em Janeiro José Manuel Palma e João Matias, da Fundação das Salinas, são ouvidos como testemunhas pela PJ de Setúbal, relatando uma história que ouviram em Alcochete que dava conta de que José Sócrates teria recebido dinheiro para aprovar a construção do Freeport.

- Em Fevereiro são feitas buscas na Câmara Municipal de Alcochete, presidida por José Inocêncio, e em três escritórios: Smith\&Pedro, SAM e SEA. As empresas visadas são de Manuel Pedro e Charles Smith, intermediários no negócio. As buscas da PJ estendem-se à sede do Freeport.

É também interrogada a secretária de Manuel Pedro e uma funcionária da 
Direção Regional do Ambiente.

- Em Agosto, a PJ envia para Inglaterra uma carta rogatória com um pedido de informação sobre movimentos bancários das contas do Freeport. Rui Leitão, funcionário da SAM, é ouvido como testemunha.

2008

- Em Maio é ouvido formalmente o chefe da divisão de urbanismo da Câmara Municipal de Alcochete, depois de três anos sem inquirições por parte da PJ de Setúbal.

- Em Setembro a directora do Departamento Central de Investigação e Acção Penal (DCIAP), Cândida Almeida, avoca o processo justificando que o caso é muito complexo. Em poucos meses realizam-se duas reuniões com a Polícia britânica para troca de informações.

2009

- Em Janeiro a PJ realiza mais buscas domiciliárias, nomeadamente na casa de Júlio Monteiro, tio de José Sócrates, no escritório de advogados Vieira de Almeida e no atelier de arquitectos Capinha Lopes.

- A 10 e 17 do mesmo mês, o Ministério Público emitiu comunicados onde esclarecia que, até àquele momento, não havia indícios do envolvimento de qualquer ministro português, do atual Governo ou de anteriores, em eventuais crimes de corrupção relacionados com o caso.

- Em Fevereiro, os empresários Charles Smith e Manuel Pedro foram ouvidos como arguidos no DCIAP, em Lisboa, e ambos ficaram sujeitos a termo de identidade e residência (TIR).

- No dia 18 do mesmo mês, o empresário Júlio Monteiro, tio de José Sócrates, é ouvido como testemunha no Tribunal de Cascais, área da sua residência, por procuradores do DCIAP.

- Em Maio o arquitecto Eduardo Capinha Lopes é constituído arguido na investigação. O gabinete de Capinha Lopes foi responsável pelo projecto do centro comercial 'outlet' em Dezembro de 2001 e foi alvo de buscas do DCIAP e da PJ em Janeiro.

- Em Junho, Carlos Guerra, antigo presidente do Instituto de Conservação da Natureza (ICN) que assinou os pareceres decisivos para o chumbo e a posterior aprovação do 'outlet' de Alcochete, em Março de 2002, foi constituído arguido no caso. Dias depois pede a demissão do cargo de Programa de Desenvolvimento Rural (PRODER).

- Também em Junho o ex-presidente da câmara de Alcochete, José Dias Inocêncio, foi constituído arguido no inquérito

- No mesmo mês, José Manuel Marques, antigo vice-presidente do Instituto de Conservação da Natureza (ICN), foi igualmente constituído arguido no 
caso. José Manuel Marques foi consultor da Câmara Municipal de Alcochete na altura em que o 'outlet' de Alcochete foi aprovado.

2010

- No dia 26 de Julho o DCIAP deu por concluída a investigação do processo Freeport.

Fonte: Diário de Notícias, especial Caso Freeport, 27 de julho de 2010

(http://www.dn.pt/especiais/interior.aspx?content_id=1627775\&

especial $=$ Caso $\% 20$ Freeport $\&$ seccao $=$ POL $\%$ CDTICA $\&$ page $=3)$

Segundo Blankenburg (2002) a corrupção política é um fenómeno recorrente que está intrinsecamente relacionado com mudanças de valores políticos, económicos e sociais, bem como a ascensão de novos grupos sociais ao poder. Para este autor um dos fatores que mais determinou nos anos 90, a eclosão na Europa Ocidental de fenómenos de corrupção política foi a mudança de padrões de clientelismo político, que estando inseridos em práticas locais, regionais e nacionais se viram confrontados com avaliações exógenas de cariz internacional.

A visibilidade do fenómeno na comunicação social acentuou-se neste último quinquénio, como demonstra o exemplo apresentado em seguida na revista Visão.

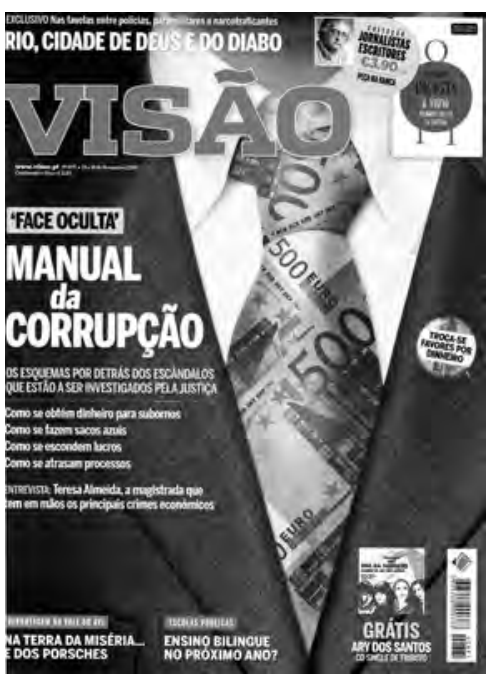

Fonte: Visão, no 871, 12 a 18 de Novembro de 2009 
As transformações das últimas décadas na Europa levaram a que o mundo dos negócios ficasse sobre grande pressão e se instalasse um clima de competição em consequência da globalização. Muitos países europeus foram obrigados a abandonar centenários procedimentos protecionistas, nomeadamente no que concerne à indústria nacional, e a investir em infraestruturas (tais como comboio, aeroportos, telecomunicações, correios e serviços) com vista a facilitar a instalação de empresas multinacionais e o comércio internacional. Este modelo económico abriu campo a uma crescente interdependência entre os negócios e a política, alimentando uma estrutura clientelística. Neste contexto, nos anos 80 e 90 os acordos do GATT, do Banco Mundial, assim como a criação das zonas de comércio livre dentro da Europa, da América e da Ásia, resultaram na abertura dos mercados nacionais e na privatização forçada das empresas dirigidas pelo Estado. As privatizações surgem simultaneamente como oportunidades para novos negócios mas também para novas formas de corrupção política e económica. Em contrapartida, o avanço da globalização e as práticas económicas que a este processo obriga, nomeadamente a homogeneização de procedimentos para concursos e abjudicações, levou à institucionalização de mecanismos de combate à corrupção: Fighting corruption on the side of bribers as well of the bribed has been one of the credos of the globalization efforts (Blankenburg (2002:154). Os países e os governos assumem coletivamente que a corrupção é um inimigo da competição internacional, obrigando assim à promoção de normas para uma justa competição no interior de um mercado livre e sancionando aqueles e aquilo que possa criar obstáculos a esta situação.

Os tipos mais frequentes de corrupção política, como se disse anteriormente são a fraude, o suborno, o clientelismo, a apropriação indevida de bens, o tráfico de influências, o favorecimento seletivo e o financiamento ilegal de partidos. Em Portugal, este último aspeto tem dominado os casos mais mediatizados como se constata no estudo empírico o "Escândalo Político em Portugal: 1991-1993 e 2002-2004", de Bruno Paixão (2010). Entre estes, que envolveram alegadas práticas de corrupção política e económica estão os casos: "Fax de Macau" (1991); "Caso Costa Freire" (1991); "Faturas falsas do Fundo Social Europeu" (1993); "Caso Moderna" (2002); "Caso Avelino Ferreira Torres" (2004); "Caso Felgueiras" (2004; "Caso Isaltino de Morais/Câmara de Oeiras" (2003). Em grande parte destes 
"casos" são detetalhadas cumplicidades entre o mundo da política, obras públicas e futebol, com a respetiva contribuição para o financiamento dos partidos e dos políticos.

A estes casos ainda se poderiam acrescentar, por exemplo, os casos amplamente mediatizados "CTT/Coimbra", "Freeport", "Face Oculta" e "Submarinos", onde as questões relativamente ao financiamento de políticos e partidos parecem estar sob constante suspeição. Como exemplo, transcreve-se o depoimento do ex-vereador da Câmara Municipal do Porto ao programa Linha da Frente da RTP1.

Programa Grande Reportagem Linha da Frente, RTP1, emitido a 30/03/2011. Título "Afinal de Contas". 40m. Resumo: "Afinal de Contas é uma reportagem sobre as derrapagens financeiras nas obras públicas em Portugal e nas parcerias público-privadas. Este trabalho conta com depoimentos do ex-juiz do Tribunal de Contas, Carlos Moreno, do ex-ministro das Obras Públicas, Ferreira do Amaral e do ex-vereador do urbanismo da Câmara Municipal do Porto, Paulo Morais".

Excertos do depoimento de Paulo Morais: ... o financiamento partidário é calamitoso...envolve duas questões: financiamento dos partidos propriamente ditos e da sua atividade...têm que arranjar recursos e fazem-no nomeadamente através desta nova Lei....Outro aspeto é o financiamento da vida privada dos próprios políticos. Há todo um conjunto de pessoas que gravitam à volta da vida política, os chamados homens da mala, que são aqueles que fazem a intermediação entre o financiador e os partidos que recebem o dinheiro. E hoje as margens de comissionamento neste tipo de negócios, que já é um negócio, estão na ordem dos 40\%. Ou seja alguém vai a um empreiteiro buscar 100 mil euros para dar ao partido e pelo caminho fica com 40 mil e dá 60 mil ao partido... 


\section{Crise, corrupção política e media}

Blankenburg (2002) demonstra que a adesão à União Europeia, de muitos países do Sul e do Leste da Europa, e a consequente desregulamentação dos media, originou uma maior competição pelo valor-notícia e uma nova cultura profissional dos jornalistas, fundada simultaneamente na competição pelo mercado de audiências e nos valores democráticos. A corrupção e o escândalo entraram no quotidiano dos media constituindo um issue sempre com dimensões e valor de mercado crescentes.

Segundo Thompson (2000:40) o escândalo político refere-se a ações ou acontecimentos que implicam certos tipos de transgressões que se tornaram conbecidas de outros e que não são suficientemente sérias para provocar uma resposta pública. O mesmo autor considera que o escândalo está muitas vezes associado à corrupção e ao suborno de tal modo que esses conceitos parecem inextricavelmente ligados (Thompson, 2000:55). Ao mesmo tempo, as democracias liberais reúnem um conjunto de fatores que tendem a promover o escândalo político, nomeadamente estratégias de visibilidade dos líderes políticos, as mudanças de tecnologias de comunicação e de vigilância, as mudanças na cultura jornalística e na cultura política, bem como a crescente regulamentação da vida política.

A crise e a corrupção política são por si só uma matéria-prima para os media pois geram fenómenos de valor acrescentado e é neste contexto que se insere a escandalização, ou seja a apresentação de uma informação sob a forma de escândalo, dentro de uma lógica de crescente competição entre meios de comunicação em busca do mercado das audiências. É necessário, ainda, ressaltar que, num primeiro momento, a imprensa (escrita, radiofónica e televisiva) apostou no jornalismo de investigação, mas o alastrar da crise económica aos media, fez com que se privilegiassem informações oferecidas por fontes anónimas, normalmente localizadas nos tribunais. Como nota Blankenburg (2002: 153), o tom das revelações dos media assume caraterísticas de espetáculo (entretenimento e ficção) servido quotidianamente aos espetadores/consumidores de informação, envolvendo, por vezes, grandes doses de imaginação criativa e algum apelo ao pânico moral, como se nota na chamada da primeira página do jornal Público: 


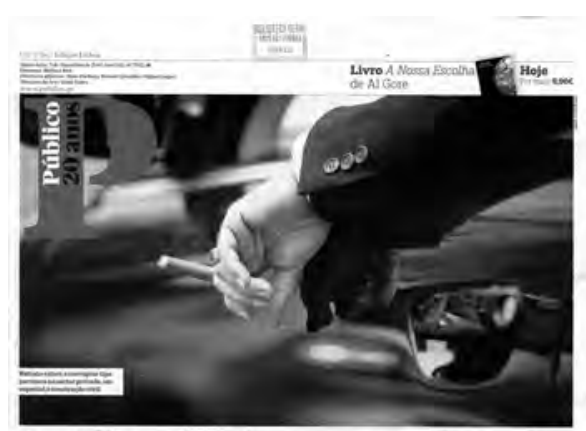

Dos 549 condenados por corrupção em dez anos só 50 tiveram pena de prisão efectiva

Um retrato do Portugal corrupto $\bullet$ Mais de 80 por cento dos inquilidos acham que a comrupcîo

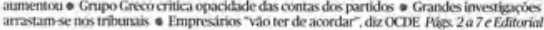

Fonte: Público, Quinta-feira, 9 de Dezembro de 2010

A estes fenómenos convém somar a convergência de interesses dos juízes e dos media no sentido de permitir a ambos enfrentar o sistema partidário. Todavia este procedimento tem como consequências os julgamentos em praça pública e a utilização dos tribunais como palcos de escandalização. A estes fatores acresce a lentidão ou a incapacidade da justiça demonstrar a ilicitude de determinados atos de corrupção o que leva os media e o ministério público a unirem-se no sentido de expor o arguido àquilo que parece ser a sua única e verdadeira punição: o escândalo público. Os media tornam-se muitas vezes um permanente palco de discurso moral e legal, definindo e redefinindo, na praça pública, o que se entende por corrupção política. Ressalva-se, no entanto, que a escandalização da corrupção política tornou-se uma estratégia de denúncia que tende a afetar a classe política e a democracia representativa como um todo, apesar de instrumentalizada por todos os políticos.

O papel dos juízes e do ministério público tornou-se especialmente visível, em diversos momentos das últimas décadas, nos países do sul da Europa. Na Itália dos anos 80, a magistratura adquiriu grande notoriedade encabeçando o movimento "mãos limpas" que evidenciou os tentáculos da corrupção política e das máfias no financiamento dos partidos. Nos anos noventa, em Espanha, foram também notórias as ações do ministério público contra a corrupção, estando assinaladas em Novembro de 2009, 730 investigações a responsáveis, públicos e políticos, de todos os partidos por corrupção.

Conforme escreve Blankenburg (2002: 154) estas diligências da justiça devem-se a uma nova geração de juízes, egressa da democratização do ensino superior 
e do alargamento da base da classe média no sul da Europa. Estes juízes têm menos ligações às elites tradicionais e assumiram, em muitos casos, a luta contra a corrupção como uma missão da sua magistratura. Movimentando-se entre legislação desadequada e morosidades processuais, os jovens juízes são tentados a considerar os jornalistas seus aliados, esquecendo que as informações, uma vez na praça pública, se autonomizam e criam dinâmicas próprias independentes da sua fonte. Como refere Leblanc (1998: 60-70), os media e a justiça têm, pelo menos, dois objetivos comuns: descobrir a verdade e fazer com que publicamente ela seja reposta. No entanto, enquanto o juiz surge aos olhos do cidadão comum como um justiceiro, cuja ação está travada por obrigações e códigos, o jornalista parece estar aparentemente mais livre, movendo-se por uma representação da justiça que transcende os limites da instituição. Esta perceção pública da justiça faz com que os media assumam a intermediação entre poderes, exercendo ora o papel de acusadores, ora de advogados de defesa, ora de juízes nos casos com maior potencial mediático. Nestes caso, é também frequente a violação do segredo de justiça, promovida pelos media através da divulgação de informações de fonte judicial, gerando um conhecimento parcial dos factos designada "informação hipótese" e os julgamentos na praça-pública.

No sentido de minimizar a crise e as denúncias de corrupção política os governos de países democráticos tendem a condicionar a informação e a controlar a informação pública.

Por exemplo, o chamado caso "Face Oculta" envolve procedimentos do governo que apontam para tentativas de controlo da informação, como demonstra a notícias do semanário Expresso:

\section{Sócrates falou do negócio PT/TVI 11 dias antes de negar conhecê-lo}

\begin{tabular}{|c|c|}
\hline $\begin{array}{l}\text { Tace } \\
\text { agua } \\
\text { so } \\
\text { achos } \\
\text { tos }\end{array}$ & $\begin{array}{l}\text { diu par } \\
\text { Estas } \\
\text { onegoc }\end{array}$ \\
\hline
\end{tabular}


O papel dos media, face ao fenómeno da corrupção é reconhecido por todas as instituições internacionais tais como a ONU, a OCDE, bem como as organizações políticas (EU), económicas (Banco Mundial, FMI) e não governamentais (Transparency International). Na perspetiva destas instituições, os media podem desempenhar um importante papel na denúncia do fenómeno e, em simultâneo, contribuir para a consciencialização da opinião pública e defesa dos interesses públicos (Heidenheimer e Johnston, 2002; Sousa e Triães, 2008).

Os intervenientes nacionais e internacionais que se debruçam sobre esta problemática concordam, contudo, que nos países ocidentais, a perceção do fenómeno é influenciada pelo tipo de cobertura jornalística realizada pelos media, nomeadamente pelo que alguns autores designam como indústria mediática do escândalo (Heidenheirmer, Johnston, Levine, 1999; Thompson, 2000).

Em Portugal há alguns estudos que se debruçam sobre a perceção da corrupção nos media. Num trabalho realizado em 2006 e 2007, sobre os traços caracterizadores da perceção que os portugueses associam às práticas de corrupção ocorridas em Portugal, Maia (2009: 115) constatou que a maior parte das pessoas recolhe informação acerca das práticas de corrupção e constrói a sua perceção acerca do problema, tendo como base os canais televisivos, bem como a imprensa. Outros estudos realizados por Sousa e Triães confirmam relativamente aos anos de 2007 e 2008, a mesma realidade. Poeschl e Ribeiro (2010), num artigo sobre as representações sociais da corrupção, apuraram que são os acontecimentos nacionais que se impõem à mente dos cidadãos, os negócios fraudulentos que povoam o mundo do futebol e da política e das instituições financeiras. A informação parece resultar dos enquadramentos mediáticos mais frequentes que tendem a destacar pessoas singulares ou casos específicos e a negligenciar análises mais abrangentes dos fenómenos.

Estes trabalhos sobre as representações sociais da corrupção focam a importância dos media para a perceção da corrupção pelos portugueses (Sousa e Triães, 2007, 2008; Maia, 2009; Sousa, 2009, 2010) mas não se debruçam sobre a relação dos media com a corrupção política ou sobre a cobertura jornalística dos fenómenos de corrupção. Como exceção refere-se um breve ensaio publicado em 2008, no $\mathrm{n}^{\circ} 12$, da Revista Trajectos, do ISCTE, da autoria de Isabel Babo-Lança, intitulado $A$ corrupção como problema público e a nova ética da confiança. Neste artigo de treze páginas a autora aborda os discursos sobre a 
corrupção e discorre sobre as questões de denúncia e desconfiança no espaço público. O livro do jornalista José Vegar e da procuradora Maria José Morgado, intitulado Fraude e Corrupção em Portugal: O inimigo sem rosto, de 2003, disserta no capítulo quinto sobre as relações entre justiça e comunicação social, incidindo sobre o segredo de justiça e as fugas de informação para os media. No trabalho de Mestrado publicado sob o título O escândalo político em Portugal, Bruno Paixão (2010) procura observar como o escândalo político, envolvendo em geral um fenómeno de corrupção política, se torna mercadoria interessante para os jornalistas e para os adversários políticos, eventuais beneficiários da aniquilação da vítima do escândalo. Por último, em março de 2011, foi editado o livro Transparência, Justiça, Liberdade: Em Memória de Saldanha Sanches, coordenado por Luís de Sousa e Domitília Soares, onde João Triães, no capítulo 1, 1 aborda o tema Acesso à informação, media e corrupção em Portugal.

Neste contexto, dado que a corrupção se pratica de forma discreta, os meios de comunicação têm um papel preponderante na difusão da informação sobre casos de corrupção (Tumber e Waisbord, 2004), mas também podem utilizar a informação para aumentar as suas vendas e obter maiores audiências (Shea, 2009). Como refere Shea (2009), só agentes que conhecem as práticas e os meandros de uma instituição têm capacidade de avaliar os procedimentos ilícitos sendo que estes nem sempre estão na posição institucional certa para os denunciar, optando muitas vezes por os silenciarem. Nesta linha, Lindstedt e Naurin (2010) consideram que a existência ou não de corrupção, tem uma correlação muito forte com a independência dos media e a liberdade de informação, constituindo estes fenómenos um indicador da qualidade da democracia e da liberdade de expressão.

\section{Algumas conclusões: notas sobre a transparência}

A sobreposição das diversas crises (acional, internacional, nacional) e as denúncias de corrupção constituíram conteúdos recorrentes, ao longo destes anos, nos meios de comunicação portugueses. Os media não ficaram imunes aos ciclos económicos dado que integram grandes grupos económicos com áreas diversificadas de interesses e ligações internacionais. A retração 
do investimento publicitário, associado às movimentações pelo controle, privado e público, das empresas de Comunicação, Informação e Media, criaram um clima de grande crispação dentro das redações das televisões, jornais e rádios, e entre estas últimas, o governo e as diversas fações partidárias. Entre 2008 e 2011 sucedem-se as acusações de interferência do governo, sobretudo do primeiro-ministro José Sócrates, junto de empresas de Comunicação Social, visando condicionar informações menos favoráveis à governação socialista. O tema da transparência tornou-se mais um issue a juntar à crise, à corrupção e ao escândalo político.

Transparência é um conceito entendido como a disponibilização de informação sobre uma instituição pública a agentes internos e externos para que possam formar uma opinião sobre ações e processos a empreender face a essa instituição. Para que haja transparência é determinante conhecer-se quem são os agentes que publicitam a informação e quais as relações que existem (ou não existem) entre as empresas dos media, do sistema político e partidário e dos grupos mediáticos, nomeadamente com a imprensa. A partir da identificação destas relações é que se pode aferir os critérios de publicitação de determinados acontecimentos, as agendas, assumidos pelos meios de comunicação os quais influenciarão não só os assuntos sobre os quais as pessoas irão pensar, mas também os pontos de vista que moldam a opinião pública (Iyengar e Simon, 1993).

A partir da análise de dados internacionais sobre diversos países Lindstedt e Naurin (2010), num artigo intitulado Transparency is not enough: making transparency effective in reducing corruption, confirmam que, tornar a informação acessível ou promulgar legislação sobre a corrupção, não é condição suficiente para a combater ou diminuir. Os autores consideram que as medidas tomadas pelos agentes públicos e governamentais com vista a tornar as instituições transparentes têm mais possibilidades de não se efetivarem, ou terem menos sucesso, que as empreendidas pelos cidadãos organizados. Estas conclusões apontam para o papel determinante dos cidadãos no combate à corrupção, nomeadamente por meio da consciencialização dos danos causados à democracia e à economia, na assunção de formas de cidadania ativa e através da ação de uma imprensa independente.

A desconfiança face às medidas tomadas pelos governos/estados fundamenta-se na perceção que existem dois tipos de transparência: a que é controlada 
pelo agente produtor da informação (o ator que produz a informação assume a responsabilidade de a publicitar) e aquela que não é controlada pelo agente produtor, ou seja a informação que é publicitada por quem não a produz e não está envolvido no processo. A primeira forma de transparência tem mais possibilidades de se revelar ineficaz, simulando apenas procedimentos formais de transparência.

Para que a transparência seja de facto um meio de prevenir a corrupção é necessário disponibilizar a informação mas, também, fazer com que chegue de forma compreensível aos potenciais prevaricadores, inibindo as suas condutas criminosas, e aos cidadãos, alertando-os para a dimensão dos crimes. Conjugam-se, assim, três fatores no combate à corrupção, a transparência das instituições, a publicitação alargada e a responsabilidade cívica.

\section{BIBLIOGRAFIA}

Aristóteles (2001). Da geração e da corrupção. São Paulo: Landy.

Aristóteles (2005). Sobre a Geração e a Corrupção. Lisboa: INCM.

Avritzer, L., Gignotto, N., Guimarães, J., Starling, H. M. M. (org.) (2008). Corrupção: ensaios e críticas. Belo Horizonte: Editora UFMG.

Blankenburg, E. (2002). From Political Clientelism to Outrighy Corruption - The rise of the Scandal Industry, pp. 149-165. In: Kotkin, Stephen \& Sajó, A. Political Corruption in transition: a sceptic's handbook. Budapeste: Central European University Press.

Campus, D. (2010). Mediatization and Personalization of Politics in Italy and France: The Cases of Berlusconi and Sarkozy. The International Journal of Press Politics. 15: 219-235.

Bobbio, N., Matteucci, N., Pasquino, G. (2004). Dicionário de Política. 2 vols.12a ed. Brasília: Editora da Universidade de Brasília.

Charron, N. (2009).The impact of Socio-Political Integration and Press Freedom on Corruption. Journal of Development Studies. 39 (4): 1-21.

Cunha, A. G. da (1982). Dicionário etimológico da língua portuguesa. São Paulo: Nova Fronteira.

Dobel, P. (1978). The corruption of the State. Los Angeles. American Political Science Review, 72 (3): 958-973.

Edelman, M. (1976). The Symbolic Uses of Politics. Champaign: University of Illinois Press.

Ferin, I. (coord.) Jornalismo e Democracia. Lisboa: Paulus. 
Filgueiras, F. (2008). Corrupção, democracia e legitimidade. Belo Horizonte: Editora UFMG.

Gambetta, D. (2002).Corruption: An Analytical Map, p. 33-56. In: Kotkin, S. \& Sajó, A. Political Corruption in transition: a sceptic's handbook. Budapeste: Central European University Press.

Heidenheirmer, A. J. \& Johnston, M. (ed.) (2002). Political Corruption: Concepts \& Contexts. (3ed.). New Jersey: The State University.

Jacobs, J. B.(2002). Dilemmas of Corruption Control, p. 81-90. In: Kotkin, S. \& Sajó, A. Political Corruption in transition: a sceptic's handbook. Budapeste: Central European University Press.

Kotkin, S. \& Sajó, A. (2002). Political Corruption in transition: a sceptic's handbook. Budapeste: Central European University Press.

Leblanc, G. Del modelo judicial a los processos mediáticos, pp. 60-70. In: Gauthier, G., Gosselin, A., Mouchon, J. (comps). Comunicacion y Politica. Barcelona: Gedisa.

Lindstedt, C. \& Naurin, D. (2009). Transparency is not enough: making transparency effective in reducing corruption. International Political Science Review. 31 (3): 301-322.

Paixão, B. (2010). O Escândalo Político em Portugal. Coimbra: Minerva.

Philp, M. (2002). Political Corruption, Democratization, and Reform, pp. 57-79. In: Political Corruption in transition: a sceptic's handbook. Budapeste: Central European University Press.

Raboy, M. \& Dagenais, B. (1992). Media, Crisis and Democracy. London: Sage

Shea, D. (1999). All scandal politics is local: ethical lapses, the Media and Congressional Elections. International journal of Press Politics 4:45-62.

Sousa, L. de \& Triães, J. (2007). Corrupção e Ética em democracia: o Caso de Portugal. Lisboa: ObercomBrief.

Thompson, J. B. (2002). O escândalo político: poder e visibilidade na era mídia. Rio de Janeiro: Vozes.

Transparency International (2005). Global Report 2004: Political Corruption. Cambridge: University Press. 